\title{
RESEARCH
}

\section{Mechanically Stretched Chromosomes as Targets for High-resolution FISH Mapping}

\author{
Maris Laan, ${ }^{1}$ Olli-P. Kallioniemi, ${ }^{2}$ Elina Hellsten, ${ }^{3}$ Kari Alitalo, ${ }^{4}$ Leena \\ Peltonen, ${ }^{3}$ and Aarno Palotie ${ }^{1,5}$
}

\begin{abstract}
'Department of Clinical Chemistry, University of Helsinki and the Laboratory Department of Helsinki University Hospital, Helsinki, Finland; ${ }^{2}$ Laboratory of Cancer Genetics, Tampere University Hospital, and the Institute of Medical Technology, University of Tampere, Tampere, Finland; ${ }^{3}$ National Public Health Institute, Department of Human Molecular Genetics, Helsinki, Finland; ${ }^{4}$ Molecular and Cancer Biology

Laboratory, The Haartman Institute, University of Helsinki, Helsinki, Finland
\end{abstract}

\begin{abstract}
When used with metaphase chromosomes, fluorescence in situ hybridization (FISH) makes it possible to localize probes to individual chromosome bands and to establish the order of probes separated by $\geqslant 2-3 \mathrm{Mb}$ in dual-color hybridizations. We evaluated the use of mechanically stretched chromosomes as hybridization targets for increased mapping resolution. Mapping resolution was tested by pair-wise hybridizations with probes from the 1p32-p33 region, spanning distances from 20 to $\sim 1500 \mathrm{~kb}$. Probes separated by $\geqslant 170 \mathrm{~kb}$ could be ordered relative to one another and to the centromere-telomere axis of the chromosome. The advantages of the technique are the simple procedure for preparing the slides, the straightforward interpretation of the results, and the ability to score the predominant order from $<10$ stretched chromosomes. However, because of the variability of stretching from one sample to another, the calculation of actual physical distances between probes is not possible. To illustrate the utility of this method, we showed that the gene for receptor tyrosine kinase TIE lies centromeric to COL9A2, RLF, and L-MYC genes at Ip32. The use of mechanically stretched chromosomes provides $\leqslant 10$-fold increased mapping resolution as compared with conventional metaphase FISH. Thus, the technique effectively bridges the gap between metaphase mapping and ultra-high-resolution mapping (1-300 kb) techniques, such as the DNA fiber FISH.
\end{abstract}

High-resolution physical mapping, ordering of probes, and construction of contigs are essential steps in positional cloning projects. Rapid developments in fluorescence in situ hybridization (FISH) techniques have paved the way for the application of new visual physical mapping methods. The use of FISH with metaphase spreads and prometaphase preparations allows the ordering of probes with 2-3- and $1-\mathrm{Mb}$ resolutions, respectively. Interphase nuclei in which the chromatin is $\sim 20$-fold less condensed than chromatin in prometaphase and paometaphase nuclei have been used as hybridization targets for ordering the probes within the range $50-1000 \mathrm{~kb}$ (Trask 1991). However, interphase FISH mapping is more demanding than the metaphase approach. It requires nuclei that are arrested perfectly in the $G_{1}$ cell cycle phase, and the ordering of probes

\footnotetext{
${ }^{5}$ Corresponding author.
}

E-MAIL aarno.palotie@hyks.mailnet.fi; FAX 358-0-471-4001. can be accomplished only after a statistical evaluation of the predominant order in $\sim 100$ nuclei.

The recently developed DNA fiber FISH techniques provide straightforward high-resolution mapping in the range 1-300 kb (Heng et al. 1992; Wiegant et al. 1992; Parra and Windle 1993; Haaf and Ward 1994a; Heiskanen et al. 1994; Senger et al. 1994). However, when using the DNA fiber FISH techniques, the mapping of probes separated by $>300 \mathrm{~kb}$ becomes increasingly problematic and the direct establishment of the telomeric-centromeric orientation is often difficult. Overall, a robust and accurate mapping technique is required in the range $300-3000 \mathrm{~kb}$. This technique would bridge the gap between (pro)metaphase FISH and DNA fiber FISH techniques.

Mechanically stretched chromosomes, prepared by cytocentrifugation of hypotonically treated cells, provide an alternative target for high-resolution FISH mapping. The application 


\section{LAAN ET AL.}

of these extended chromosomes for the ordering of yeast artificial chromosome (YAC) clones separated by $\sim 1 \mathrm{Mb}$ (Haaf and Ward 1994a) and for the structural analysis of $\alpha$-satellite DNA and proteins, has been reported (Haaf and Ward 1994b).

In this report we evaluated the use of mechanically stretched chromosomes in the application of high-resolution mapping of probes that are too close to be reliably ordered and oriented on (pro)metaphase chromosomes and too far to be analyzed using DNA fiber FISH. We used the stretched chromosomes as a target for FISH analysis in the human 1p32-33 chromosomal region, which has been well-characterized recently by physical mapping using both PFGE (Hellsten et al. 1995) and DNA fiber FISH (Heiskanen et al. 1995). Also, we report the refined localization of the gene for the receptor tyrosine kinase TIE, mapped earlier to $1 \mathrm{p} 33-34$ by radioactive in situ hybridization (Partanen et al. 1992).

\section{RESULTS}

\section{Resolution on Mechanically Stretched Chromosomes}

Seven different probes mapping to a $\sim 1-\mathrm{Mb}$ region at 1p32-33 were used to analyze the resolu- tion of FISH mapping to stretched chromosomes (Fig. 1). Pair-wise two-color hybridizations on extended chromosomes, demonstrated in Figure 2, were compared with the known physical distances among the hybridized probes, determined by traditional pulsed-field gel electrophoresis (PFGE)-based long-range mapping (Hellsten et al. 1995). Figure 3 shows the percentage of resolvable signals in pair-wise hybridizations as a function of the known intervals between the probes. Each bar represents the result of the analysis of 35-53 chromosomes. If any two probes were $<140 \mathrm{~kb}$ apart, their hybridization signals were detected as a single yellowish spot in $65 \%-80 \%$ of the cases. With increasing distance between the probes, fractions of chromosomes with resolvable signals increased. Probes that were $\gg 170$ $\mathrm{kb}$ apart could be separated and ordered in $>50 \%$ of the analyzed chromosomes. In each case, the orientation along the centromeric-telomeric axis also could be defined. The centromere of chromosome 1 was identified by intensive DAPI staining of the heterochromatin region. An inverse, incorrect order of a signal pair was detected in only $5 \%-10 \%$ of the chromosomes, indicating that the stretching obtained by centrifugation usually allowed retention of the centromerictelomeric orientation of the chromosome. Chro-

$100 \mathbf{~ k b}$
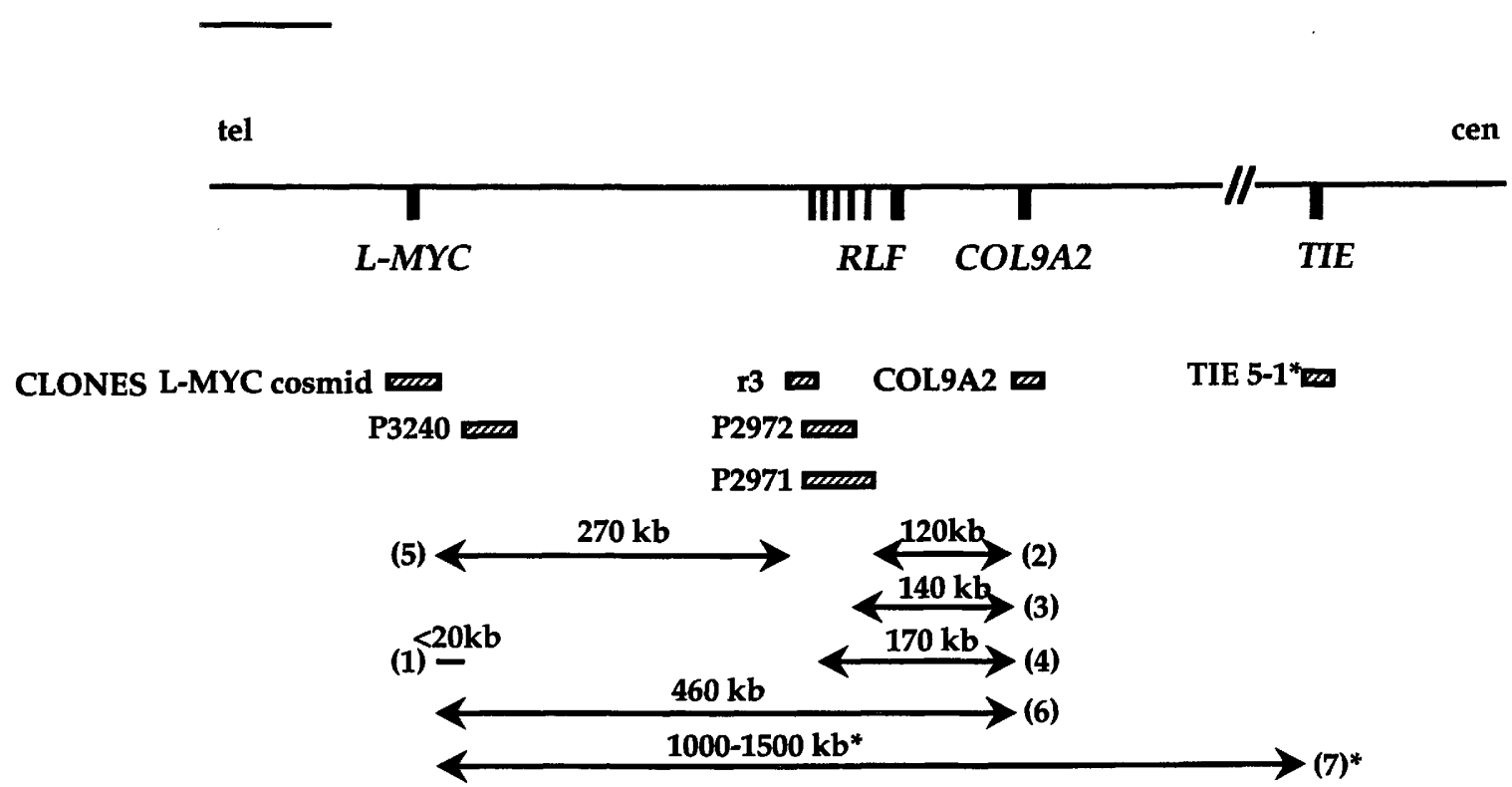

Figure 1 The locations of seven genomic clones on the human chromosome 1p32-33 region (based on Heiskanen et al. 1995; Hellsten et al. 1995). The following probe pairs were used: (1) L-MYC cosmid/P3240; (2) P2972/COL9A2; (3) P2971/COL9A2; (4) r3/COL9A2; (5) L-MYC cosmid/r3; (6) L-MYC cosmid/COL9A2; and (7) L-MYC cosmid/TIE 5-1. ( $\left.{ }^{*}\right)$ The clone TIE 5-1 was incorporated on the map on the basis of the results of this study. 


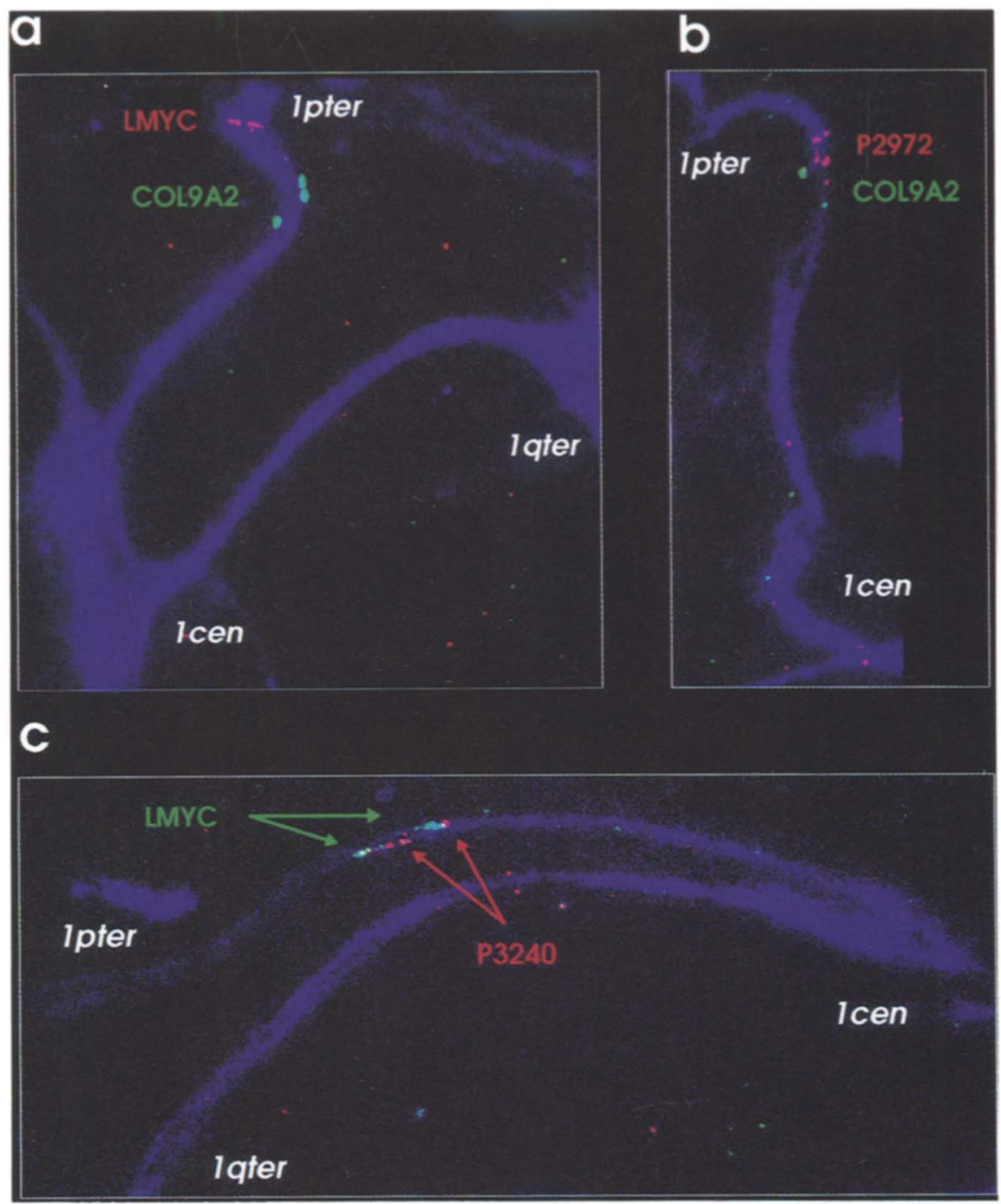

Figure 2 Digital three-color images of two-color hybridizations to stretched chromosomes. (a) L-MYC cosmid-XRITC (38 kb)/COL9A2-FITC (19 kb), probe interval $270 \mathrm{~kb}$. (b) P2972-XRITC (40 kb)/COL9A2-FITC (19 kb), probe interval $140 \mathrm{~kb}$. (c) L-MYC cosmid-FITC (38 kb)/P3240-XRITC (40 kb), probe interval $<20 \mathrm{~kb}$. The distances between the probes were obtained according to PFGE mapping data (Hellsten et al. 1995). In all cases, the orientation of the probes along the centromeric-telomeric axis is seen and hybridization signals are detectable on both chromatids of each chromosome. The centromeres were distinguished on the basis of intensive DAPI staining of the heterochromatin region (data not shown). In $c$, the orientation of the large hybridized probes, L-MYC cosmid and P3240 (both $40 \mathrm{~kb}$ ), separated by $<20 \mathrm{~kb}$ can be resolved. Two strings of linear signals on both chromatids indicated that this region of the chromosome was highly stretched.

mosomes with inverted probe orders were detected more often when using probes of small size located close to each other.

Differences in probe size did not influence the hybridization frequency significantly. Hybridization frequency varied from $85 \%$ for the $\mathrm{r} 3$

\section{STRETCHED CHROMOSOMES}

probe $(17 \mathrm{~kb})$ and $C O L 9 A 2$ (19 kb) up to $\sim 100 \%$ for $P_{1}$ clones (40-60 kb). Because of the frequent "string of beads" nature of hybridization signals, probe size was relevant in resolving clones located close to each other. The probes with longer inserts were advantageous in detecting the orientation of the two probes, even if they were partly overlapping (Fig. 2c).

In the triple-labeling experiments, the interpretation of the signal order was more complicated. The order of three probes could be determined if each of the probes was separated by $>400-500 \mathrm{~kb}$ (data not shown).

Establishment of the order of probes in stretched interphase nuclei on the cytocentrifuged preparations proved unsuccessful because of the difficult interpretation of the signal order in the three-dimensional structure of nuclei projected onto a two-dimensional plane.

\section{Evaluation of the Variations in Chromosome Stretching}

To determine the variations in chromosome stretching during cytocentrifugation, four probes were hybridized to the mechanically stretched chromosomes; in each case, lengths of 20-35 signals on extended chromosomes were determined. For the most decondensed chromosomes, the hybridization resulted in a string-of-beads appearance, similar to that seen typically in DNA fiber FISH. The results summarized in Table 1 demonstrate that the differences in the mean lengths of the probes $(\mu \mathrm{m})$ correlated with their known insert size in kilobases. However, the calculated high coeffi- 
LAAN ET AL.

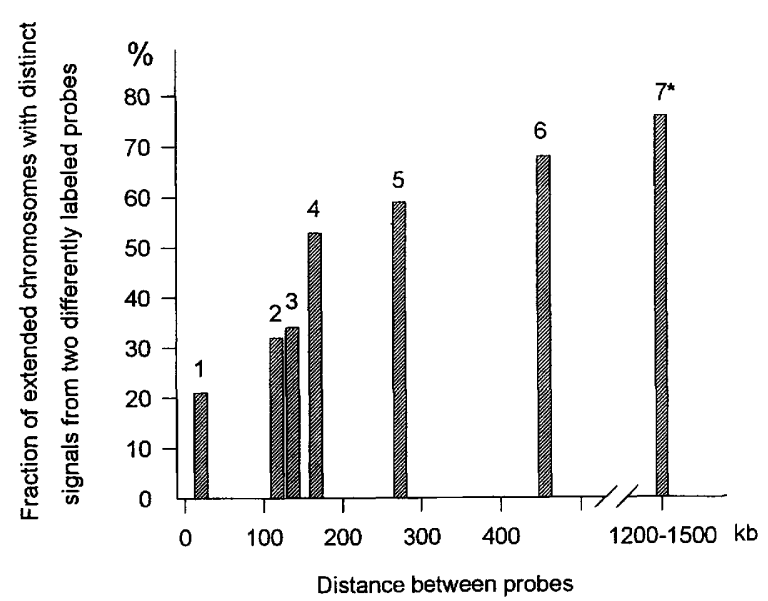

Figure 3 Estimated resolution of FISH using mechanically stretched chromosomes. The fraction of chromosomes with the distinct signals from two hybridized probes detected by different fluorochromes was plotted as a function of the known distance between the probes (see Fig. 1). Each bar represents the result of the analysis of 35-53 extended chromosomes. In the remaining cases, the signals were detected as a single yellowish hybridization spot; clear loci of the signals could not be identified because of the destruction of the chromosomal morphology. (1) L-MYC cosmid/P3240; (2) P2972/ COL9A2; (3) P2971/COL9A2; (4) r3/COL9A2; (5) L-MYC cosmid/r3; (6) L-MYC Cosmid/COL9A2; (7) L-MYC cosmid/TIE 5-1*. $\left(^{*}\right)$ The distance between the L-MYC cosmid and TIE 5-1 was estimated on the basis of the results of this study.

cient of variation (78\%-93\%) reflected the variation in the extent of stretching among individual chromosomes. Therefore, no gap size measurements were performed for the probe pairs analyzed. It was determined that the mechanically stretched chromosomes can only provide reliable information on the order of probes and not on the actual physical distances on the chromosomes.

\section{Refined Localization of the Receptor Tyrosine Kinase TIE Gene}

Mechanically stretched chromosomes were used for the assessment of the TIE receptor tyrosine kinase gene, relative to the three other genespecific probes mapping to this region ( $L-M Y C$ cosmid/r3/COL9A2). TIE has been mapped previously to $1 \mathrm{p} 33-34$. On metaphase chromosomes, the signals of the L-MYC cosmid and TIE 5-1 probes were usually overlapping or were not clearly resolvable (Fig. 4c). Pair-wise hybridiza- tion of the TIE 5-1 probe with either the L-MYC cosmid, $r 3$, or COL9A2 clones indicated a more centromeric localization of the TIE 5-1 probe if compared with any of these probes (Fig. 4a,b). This order was seen in $70 \%-75 \%$ of stretched chromosomes. The two signals could not be resolved on the remaining chromosomes. The results of these experiments on mechanically stretched chromosomes indicated that the order of the genes in the analyzed chromosomal region was TEL-L-MYC-RLF-COL9A2-TIE-CEN.

A precise estimation of the gap between $L-M Y C$ and TIE could not be established. However, because the probes for $L-M Y C$ cosmid and TIE-51 could be separated in only a few of the standard metaphase chromosomes, it is likely that the distance between the two loci is $<2-3 \mathrm{Mb}$ (Fig. 4c). On the other hand, $75 \%$ of the mechanically stretched chromosomes demonstrated two distinct hybridization signals (Figs. 3 and 4b). Using these two hypotheses, the distance between TIE 5-1 and $L-M Y C$ cosmid was estimated to be $<2$ $\mathrm{Mb}$ but $>1 \mathrm{Mb}$.

\section{DISCUSSION}

The aim of this study was to validate the use of mechanically stretched chromosomes for ordering probes that are too close together to be reliably ordered and positioned by metaphase and prometaphase FISH and too distant to be analyzed by fiber FISH.

The results indicated that the use of mechanically stretched chromosomes as a hybridization target for FISH would present $a \leqslant 10$-fold higher degree of mapping resolution than could be obtained with traditional metaphase FISH techniques. Probes separated by $\$ 170 \mathrm{~kb}$ could be resolved on stretched chromosome preparations. Furthermore, probes located closer together could be separated with maximally extended chromosomes. Because of the linear extent signals from larger probes, their resolution proved to depend on both the distance between the probes and their insert lengths (Fig. 2).

When used with stretched chromosomes, FISH is preferably a technique for ordering probes, not for localization of unknown probes to specific regions of chromosomes. The morphology of mechanically stretched chromosomes is significantly distorted so that little if any banding pattern is discernible, but the centromeretelomere orientation can usually be established. Centromeres can be identified by DAPI staining 
STRETCHED CHROMOSOMES

Table 1. Mean lengths of the signals produced by different probes hybridized to mechanically stretched chromosomes

\begin{tabular}{llll}
\hline Probe & ${\text { Length }(\mathrm{kb})^{\mathbf{a}}}$ & ${\text { Length }(\mu \mathrm{m})^{\mathrm{a}, \mathrm{b}}}$ & S.D. \\
\hline$r 3$ & $4.2+6+7$ & $0.88(0.4-1.8)$ & 0.81 \\
COL9A2 & 19 & $1.27(0.4-3.1)$ & 1.00 \\
L-MYC cosmid & 38 & $1.98(0.4-5.3)$ & 1.53 \\
P2971 & 60 & $3.52(0.4-10.6)$ & 3.13 \\
\hline
\end{tabular}

an each case the length of 20-35 signals was determined.

bRange; diameter of an average fluorescent spot (0.4) detected as a hybridization signal on minimally stretched chromosomes. the physical map of the 1 p32-33 by localizing the gene for the receptor tyrosine kinase TIE centromeric to the $C O L 9 A 2$, $R L F$, a n d $L$-MYC genes. Furthermore, the degree of stretching is

of the heterochromatin region or by using $\alpha$-centromere-specific probes. However, BrdU-based replication banding usually did not allow the identification of chromosomal bands.

To illustrate the utility of using FISH on mechanically stretched chromosomes, we improved variable from one slide to another, from one metaphase to another, and from one chromosome to another. Different preparations vary greatly, for example, the number of cells used per slide. Thus, no quantitative information on precise probe distances can be obtained.

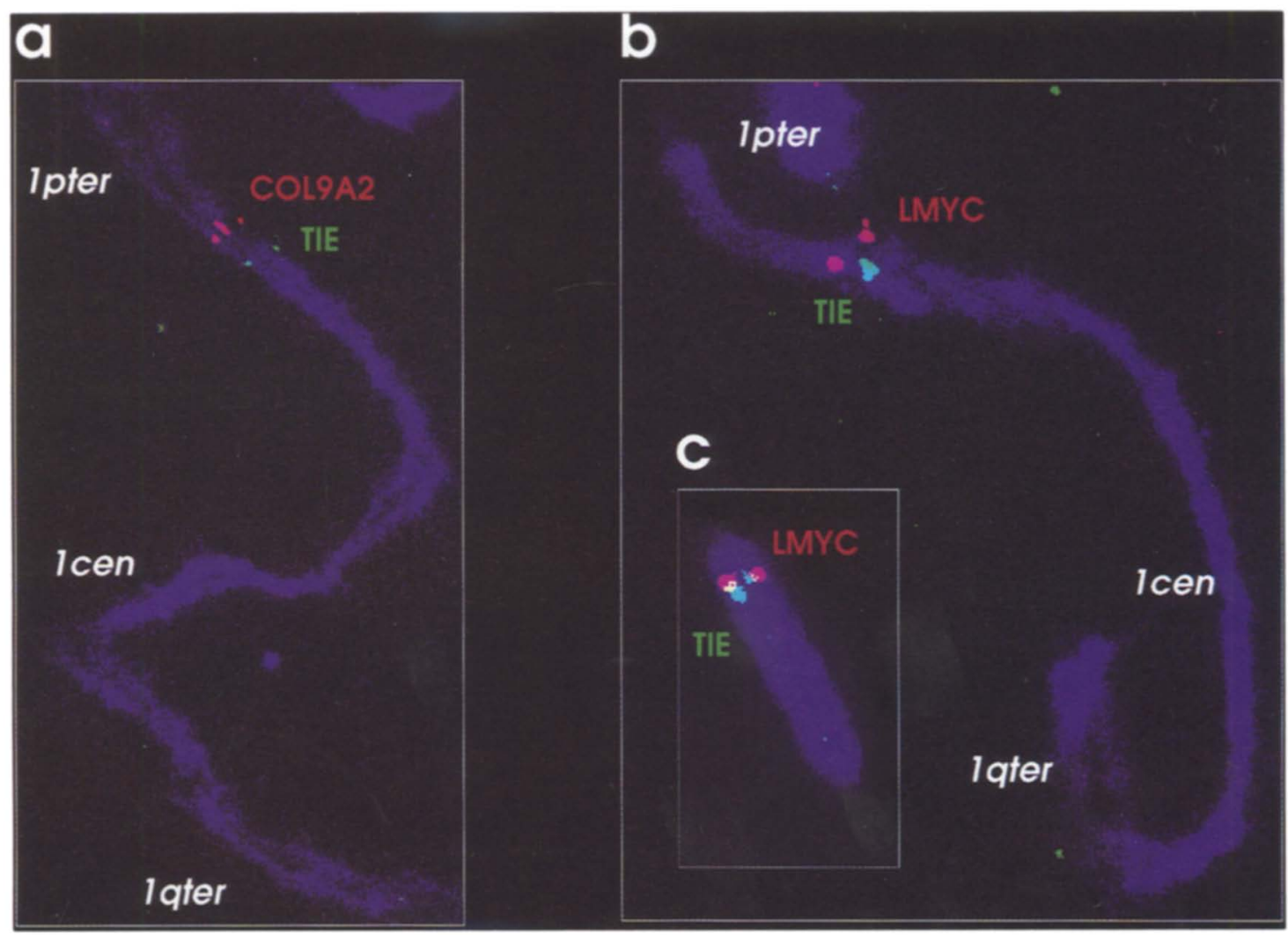

Figure 4 Digital images illustrating the refined localization of the receptor tyrosine kinase TIE gene. ( $a$ ) COL9A2-XRITC/TIE 5-1-FITC hybridized to the mechanically stretched chromosomes. COL9A2, previously the most centromeric of the three genes known in the characterized region, appears to be more telomeric than the TIE gene. (b) L-MYC cosmid-XRITC/TIE 5-1-FITC hybridized to the mechanically stretched chromosomes. L-MYC is clearly more telomeric. (c) Standard metaphase FISH analysis of cohybridized L-MYC cosmid-XRITC/TIE 5-1FITC. In most cases, the order of the probes could not be reliably established. 


\section{LAAN ET AL.}

Several prometaphase and prophase preparation techniques described in the literature have also been used in FISH mapping and have been found to provide resolution in the "submegabase" range (Lebo et al. 1992; Inazawa et al. 1994). However, obtaining such preparations by using, for example, topoisomerase II inhibitors, might be complicated. In contrast, the preparation of mechanically stretched chromosomes is technically easy and straightforward and requires no pretreatment steps; thus, it can be adopted by any laboratory with experience in FISH. Interphase FISH mapping, also providing a 50- to $1000-\mathrm{kb}$ resolution, is complicated by the chromatin structure that follows a random-walk model (van den Engh et al. 1992). Therefore, this necessitates the projection of the FISH signals to a two-dimensional plane and statistical processing of the data. As compared with interphase nuclei, the structures obtained from cytocentrifugation of chromosomes are more organized, as they retain the centromeric-telomeric orientation of the chromosome. An added advantage in using cytocentrifugation is that it is sufficient to analyze the predominant order from only a few (510) stretched chromosomes. The examination of one cytocentrifugation preparation takes $\sim 0.5 \mathrm{hr}$. Although metaphases are easily distinguishable from interphase nuclei, the speed of the scoring of stretched chromosomes increases with the experience.

In their paper describing the use of mechanically stretched chromosomes in FISH mapping, Haaf et al. (1994a) were able to map YAC clones separated by $1 \mathrm{Mb}$. The present data suggest that under optimal conditions the resolution achieved by the technique reported here can be even better. However, there are several methodological issues that may affect the resolution limit, and these are currently being studied in detail. For example, our preliminary experience from the mapping chromosome 21 (M. Heiskanen, unpubl.) suggests that this small acrocentric chromosome is not stretched as easily as the region on chromosome 1 studied here. Additionally, it is important to recognize that the degree of stretching also varies greatly from one region of a chromosome to another.

In conclusion, the use of FISH in mechanically stretched chromosomes ideally fills the gap between the ranges covered by the DNA fiber FISH (1-300 kb) and traditional metaphase FISH mapping techniques $(>2-3 \mathrm{Mb}$ ). For mapping of any unknown probe, it is preferable to start by using regular metaphase FISH approximate the location of the chromosomal locus. The use of FISH in stretched chromosomes then would help to establish a more accurate order of probes in a specific region. When probes are too close together to be ordered on stretched chromosomes, the DNA fiber FISH technique can be used.

\section{METHODS}

\section{Preparatiaon of Mechanically Stretched Chromosomes}

Mechanically stretched chromosomes were prepared essentially as described by Haaf and Ward (1994b), with slight modifications. Phytohemagglutinin-stimulated lymphocytes from a healthy adult were cultured for 3 days in RPMI 1640 medium (GIBCO-BRL). Bromodeoxyuridine (BrdU) was added on the third day as described by Lemieux et al. (1992). Cells were washed in PBS [136 mM $\mathrm{NaCl}_{2}, 2 \mathrm{mM} \mathrm{KCl}, 10.6 \mathrm{mM} \mathrm{Na}_{2} \mathrm{HPO}_{4} 1.5 \mathrm{mM} \mathrm{KH}_{2} \mathrm{PO}_{4}(\mathrm{pH}$ 7.3)] by centrifuging at $1000 \mathrm{rpm}$ for $10 \mathrm{~min}$, and then treated with a hypotonic solution consisting of $10 \mathrm{~mm}$ HEPES (pH 7.3), $30 \mathrm{~mm}$ glycerol, 10. $\mathrm{mM} \mathrm{CaCl}_{2}$, and 0.8 mM $\mathrm{MgCl}_{2}$ (Stenman et al. 1975) for 5-15 min. Next, 0.5$\mathrm{ml}$ aliquots of the hypotonic cell suspension were cytocentrifuged (Cytospin 2, Shandon), to glass slides cleaned with ethanol at 800-1200 rpm for 4-15 min. The cells were harvested, and 2000-4500 cells were used for each slide preparation. Preparations were fixed in methanol at $-20^{\circ} \mathrm{C}$ for 15-45 min and used for hybridizations on the same day, or stored at room temperature for $\leqslant 1$ month. In the latter case, slides were refixed before hybridization in methanol at $-20^{\circ} \mathrm{C}$ for $30 \mathrm{~min}$.

The slides were examined briefly before hybridization for the selection of those with proper density. A higher density of cells per slide resulted in poorly stretched chromosomes and an excess of cytoplasmic material, whereas a lower density of cells gave metaphase spreads that were too extended and where single chromosomes were barely identifiable. From $60 \%$ to $75 \%$ of the cytocentrifugation preparations were satisfactory. Usually, 2-20 metaphase spreads of stretched chromosomes, without broken arms or highly deformated structures, were obtained per slide.

\section{Probes}

The cosmid clone ICRFC112L0386, referred here to as an $L-M Y C$ cosmid (38 kb), contains the $L-M Y C$ gene (Hellsten et al. 1995). Three adjacent plasmid subclones, $r 3-7.0$ (7 $\mathrm{kb}), r 3-6.0(6 \mathrm{~kb})$, and $r 3-4.2(4.2 \mathrm{~kb})$, of the $R L F$ genomic clone (Heiskanen et al. 1995) are referred to here in combination as the $\mathrm{r} 3$ probe. The $P_{1}$ clones $P 2971(60 \mathrm{~kb})$ and $P 2972$ (40 kb) have been isolated using PCR primers originating from the $R L F$ subclone $r 3-6.0$, and the $\mathrm{P}_{1}$ clone $P 3240(40 \mathrm{~kb})$ has been isolated using primers generated from the $L$-MYC cosmid ICRFC112M0287 (Heiskanen et al. 1995).

The COL9A2 $\lambda$ clone $12 B 121(19 \mathrm{~kb})$ was a kind gift from Dr. Matthew Warman (Harvard Medical School, Boston, MA). The TIE genomic $\lambda$ clone 5-1 (15 kb) was isolated 


\section{STRETCHED CHROMOSOMES}

as described by Korhonen et al. (1995). The clones are referred as COL9A2 and TIE 5-1, respectively, in this report.

\section{FISH}

FISH was performed with either biotin-11-dUTP-labeled (Sigma Chemical) or digoxigenin-11-dUTP-labeled (Boehringer Mannheim) probes (Nick Translation Reagent Kit BRL), using slight modifications of the standard protocols (Lichter et al. 1988). The size range of the labeled probe fragments was $300-1000 \mathrm{bp}$.

The hybridization mixture contained $20-40 \mathrm{ng}$ of each of the labeled probes with 10- to 30-fold excess of unlabeled Cot-1 DNA (Life Technologies, Gaithersburg, MD) for competition as well as $1 \mu \mathrm{g}$ of herring sperm DNA in a $5-\mu$ l solution of $50 \%$ formamide and $10 \%$ dextran sulfate in $2 \times$ SSC. Prior to hybridization, a 15- to $25-\mathrm{min}$ preannealing was done at $37^{\circ} \mathrm{C}$. The preparations were hybridized under a round coverslip ( $13 \mathrm{~mm}$, Menzel-Gläser).

After posthybridization washes, hybridized probes were visualized by immunofluorescence. Biotinylated probes were detected using XRITC-conjugated avidin D, followed by biotinylated goat anti-avidin $\mathrm{D}$ and another layer of avidin-XRITC (all from Vector Laboratories, Burlingame, CA). For the digoxigenin-labeled probes, mouse anti-digoxigenin (Boehringer Mannheim) and fluoresceinconjugated sheep anti-mouse and donkey anti-sheep antibodies (both from Sigma Chemical) were used. Chromosomal DNA was stained with $0.025 \mu \mathrm{g} / \mathrm{ml}$ of DAPI (Sigma).

\section{Analysis of Hybridization Signals}

The slides were examined using a Zeiss Axiophot microscope (Carl Zeiss, Oberkochen, Germany) equipped with a $100 \times$ objective [numerical aperture (NA) 1.25] using Chromatech multiband pass filters (Chroma Technology, Brattleboro, VT). Photographs were taken with Kodak Ektrachrome ASA 400 color slide film (Eastman Kodak, Rochester, NY). A digital multicolor image analysis system also was used. This system is based on a Nikon SA fluorescence microscope (Tokyo, Japan) equipped with $60 \times$ Plan-Apo objective, multiband pass filters (Chroma Technology, Brattleboro, VT), and a Xillix charge-coupled device (CCD) camera (Vancouver, BC) interfaced to a Sun LX workstation (Sun Microsystems, Mountain View, CA) (Kallioniemi et al. 1994).

Signal lengths of the probes were measured from photographic slides projected on a wall. Conversion of the projected lengths in centimeters into actual lengths in micrometers was done using a scale bar that was photographed at the same magnification as the samples.

\section{ACKNOWLEDGMENTS}

We thank Dr. Matthew Warman for the COL9A2 probe, Drs. Juha Partanen and Jaana Korhonen for the genomic TIE 5-1 probe, Dr. Mervi Heiskanen for useful discussions, Dr. Ritva Karhu for helping with digital imaging, and Mervi Eeva and Maritta Putkiranta for intelligent technical assistance. We also thank the members of the Resource for Molecular Cytogenetics (University of California, Berkeley, CA) for providing help and software for digital image analysis. This work was supported by a grant from the Academy of Finland and an equipment grant from the Medical Research Fund of the Tampere University Hospital. M.L. was supported by a fellowship from the Viro Säätiö (Estonian Foundation in Finland) and Centre for International Mobility (Helsinki); E.H. was supported by a fellowship from the Helsinki University 350th Anniversary Fund (Helsingin Yliopiston 350-vuotisäätiö).

The publication costs of this article were defrayed in part by payment of page charges. This article must therefore be hereby marked "advertisement" in accordance with 18 USC section 1734 solely to indicate this fact.

\section{REFERENCES}

Haaf, T. and D.C. Ward. 1994a. High-resolution ordering of YAC contigs using extended chromatin and chromosomes. Hum. Mol. Genet. 3: 629-633.

1994b. Structural analysis of $\alpha$-satellite DNA and centromere proteins using extended chromatin and chromosomes. Hum. Mol. Genet. 3: 697-709.

Heiskanen, M., R. Karhu, E. Hellsten, L. Peltonen, O.-P. Kallioniemi, and A. Palotie. 1994. High resolution mapping using fluorescence in situ hybridization to extended DNA fibers prepared from agarose-embedded cells. BioTechniques 17: 928-933.

Heiskanen, M., E. Hellsten, O.-P. Kallioniemi, T. Mäkelä, K. Alitalo, L. Peltonen, and A. Palotie. 1995. Visual mapping of a $500 \mathrm{~kb}$ region on chromosome $1 \mathrm{p} 32$ by fiber FISH. Genomics (in press).

Hellsten, E., J. Vesa, M. Heiskanen, T.T. Mäkelä, I. Järvelä, J.K. Cowell, S. Mead, K. Alitalo, A. Palotie, and L. Peltonen. 1995. Identification of YAC clones for human chromosome $1 \mathrm{p} 32$ and physical mapping of the infantile neuronal ceroid lipofuscinosis (INCL) locus. Genomics 25: $404-412$.

Heng, H.H.Q., J. Squire, and L.C. Tsui. 1992.

High-resolution mapping of mammalian genes by in situ hybridization to free chromatin. Proc. Natl. Acad. Sci. 89: 9509-9513.

Inazawa, J., T. Ariyama, T. Tokino, A. Tanigami, Y. Nakamura, and T. Abe. 1994. High resolution ordering of DNA markers by multi-color fluorescent in situ hybridization of prophase chromosomes. Cytogenet. Cell Genet. 65: 130-135.

Kallioniemi, O.-P., A. Kallioniemi, L. Mascio, D. Sudar, D. Pinkel, L. Deaven, and J.W. Gray. 1994. Physical mapping of chromosome 17 cosmids by fluorescence in situ hybridization and digital image analysis. Genomics 20: $125-128$.

Korhonen, J., I. Lahtinen, M. Halmekytö, L. Alhonen, J. Jänne, D. Dumont, and K. Alitalo. 1995. Endothelial specific gene expression directed by the TIE gene promoter in vivo. Blood (in press).

Lebo, R.V., E.D. Lynch, T.D. Bird, M.S. Golbos, D.F. Barker, P. O'Connell, and P.F. Chance. 1992. Multicolor in situ hybridization and linkage analysis order 


\section{LAAN ET AL.}

Charcot-Marie-Tooth type I (CMTIA) gene-region marker. Am. J. Hum. Genet. 50: 42-55.

Lemieux, N., B. Dutrillaux, and E. Viegas-Péquignot. 1992. A simple method for simultaneous R- or G-banding and fluorescence in situ hybridization of small single-copy genes. Cytogenet. Cell Genet. 59: 311-312.

Lichter, P., T. Cremer, L. Borden, L. Manuelidis, and D.C. Ward. 1988. Delineation of individual human chromosomes in metaphase and interphase cells by in situ suppression hybridization using recombinant DNA libraries. Hum. Genet. 80: 224-234.

Parra, I. and B. Windle. 1993. High resoluion visual mapping of stretched DNA by fluorescent hybridization. Nature Genet. 5: 17-21.

Partanen, J., E. Armstrong, T.P. Mäkelä, J. Korhonen, M. Sandberg, R. Renkonen, S. Knuutila, K. Huebner, and K. Alitalo. 1992. A novel endothelial cell surface receptor tyrosine kinase with extracellular epidermal growth factor homology domains. Mol. Cell. Biol. 12: 1698-1707.

Senger, G., T.A. Jones, H. Fidlérova, P. Sanséau, J. Trowsdale, M. Duff, and D. Sheer. 1994. Released chromatin: Linearized DNA for high-resolution fluorescence in situ hybridization. Hum. Mol. Genet. 3: $1275-1280$.

Stenman, S., M. Rosenqvist, and N.R. Ringertz. 1975. Preparation and spread of unfixed metaphase chromosomes for immunofluorescence staining of nuclear antigens. Exp. Cell Res. 90: 87-94.

Trask, B.J. 1991. Fluorescence in situ hybridization: Applications in cytogenetics and gene mapping. Trends Genet. 7: 149-154.

van den Engh, G., R. Sachs, and B.J. Trask. 1992. Estimating genomic distances from DNA sequences location in cell nuclei by random walking model. Science 257: 11410-1412.

Wiegant, J., W. Kalle, L. Mullenders, S. Brookes, J.M.N. Hoovers, J.G. Dauwerse, G.J.B. van Ommen, and A.K. Raap. 1992. High-resolution in situ hybridization using halo-preparations. Hum. Mol. Genet. 8: 587-591.

Received April 24, 1995; accepted in revised form June 9, 1995. 


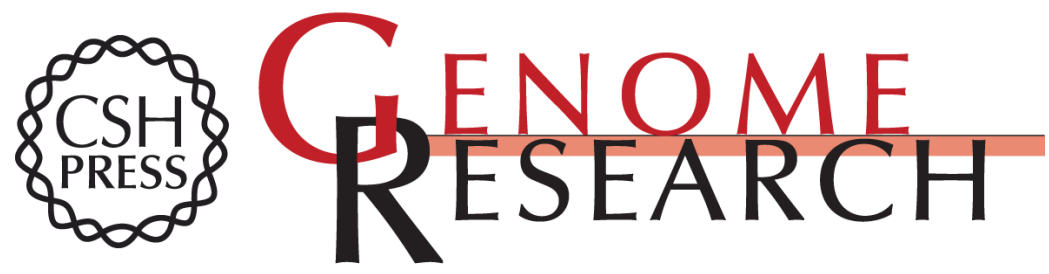

\section{Mechanically stretched chromosomes as targets for high-resolution FISH mapping.}

M Laan, O P Kallioniemi, E Hellsten, et al.

Genome Res. 1995 5: 13-20

Access the most recent version at doi:10.1101/gr.5.1.13

References This article cites 17 articles, 2 of which can be accessed free at:

http://genome.cshlp.org/content/5/1/13.full.html\#ref-list-1

\section{License}

Email Alerting Receive free email alerts when new articles cite this article - sign up in the box at the Service top right corner of the article or click here.

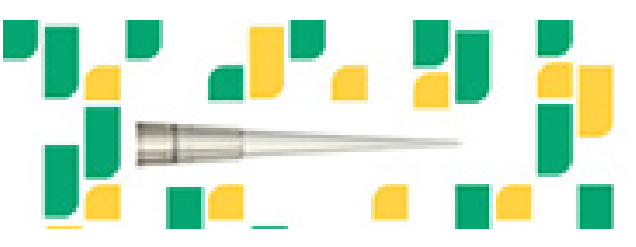

To subscribe to Genome Research go to: https://genome.cshlp.org/subscriptions 